\title{
Influência da dengue na infecção odontogênica
}

\section{Influence of dengue on odontogenic infection \\ Influencia del dengue em la infección odontogênica}

Recebido: 15/03/2021 | Revisado: 21/03/2021 | Aceito: 24/03/2021 | Publicado: 03/04/2021

Mirela Caroline Silva

ORCID: https://orcid.org/0000-0002-9455-3807 Universidade Estadual Paulista "Júlio de Mesquita Filho", Brasil E-mail: mirela_carol12@hotmail.com Tiburtino José de Lima Neto

ORCID: https://orcid.org/0000-0002-8297-4057 Universidade Estadual Paulista "Júlio de Mesquita Filho", Brasil E-mail: tiburtinoneto@hotmail.com Natália dos Santos Sanches

ORCID: https://orcid.org/0000-0003-0729-6505 Universidade Estadual Paulista "Júlio de Mesquita Filho", Brasil E-mail: naahssanches@gmail.com

Anderson Maikon de Souza Santos

ORCID: https://orcid.org/0000-0001-9371-9417 Universidade Estadual Paulista "Júlio de Mesquita Filho", Brasil E-mail: andersonmaikon@hotmail.com

Kim Henderson Carmo Ribeiro

ORCID: https://orcid.org/0000-0002-5242-2227

Universidade Estadual Paulista "Júlio de Mesquita Filho", Brasil E-mail: kimhenderson@hotmail.br

Cristian Statkieviez

ORCID: https://orcid.org/0000-0001-7973-2455

Universidade Estadual Paulista "Júlio de Mesquita Filho", Brasil E-mail: C.statkievicz@gmail.com

Barbara Ribeiros Rios

ORCID: https://orcid.org/0000-0002-5389-5536 Universidade Estadual Paulista "Júlio de Mesquita Filho", Brasil E-mail: barbarariios@outlook.com

William Phillip Pereira da Silva

ORCID: https://orcid.org/0000-0003-4172-7217

Universidade Estadual Paulista "Júlio de Mesquita Filho", Brasil E-mail: william_phillip@hotmail.com

Francisley Ávila de Souza

ORCID: https://orcid.org/0000-0002-1427-071X

Universidade Estadual Paulista "Júlio de Mesquita Filho", Brasil

E-mail: francisley.avila@unesp.br

Osvaldo Magro Filho

ORCID: https://orcid.org/0000-0002-9821-2479

Universidade Estadual Paulista "Júlio de Mesquita Filho", Brasil

E-mail: Osvaldo.magro@unesp.br

Idelmo Rangel Garcia Junior

ORCID: https://orcid.org/0000-0001-8892-781X

Universidade Estadual Paulista "Júlio de Mesquita Filho", Brasil

E-mail: irgcirurgia@gmail.com

Daniela Ponzoni

ORCID: https://orcid.org/0000-0001-5928-0914

Universidade Estadual Paulista "Júlio de Mesquita Filho", Brasi

E-mail: daniela.ponzoni@unesp.br

Ana Paula Farnezi Bassi

ORCID: https://orcid.org/0000-0002-0031-4953

Universidade Estadual Paulista "Júlio de Mesquita Filho", Brasil

E-mail: ana.bassi@unesp.br

Alessandra Marcondes Aranega

ORCID: https://orcid.org/0000-0001-5856-7972

Universidade Estadual Paulista "Júlio de Mesquita Filho", Brasil

E-mail: daniela.ponzoni@unesp.br

Leonardo Perez Faverani

ORCID: https://orcid.org/0000-0003-2249-3048

Universidade Estadual Paulista "Júlio de Mesquita Filho", Brasil

E-mail: Leonardo.faverani@unesp.br 


\begin{abstract}
Resumo
Fundamento: A dengue é uma doença viral endêmica transmitida por mosquito da espécie Aedes aegypti e Aedes albopictus que causa uma queda no sistema imunológico do hospedeiro pela sobrecarga no combate ao vírus e deixa o organismo mais susceptível a infecções oportunistas. A infecção odontogênica pode ter seu quadro agravado em pacientes infectados pela dengue, tornando o tratamento mais complexo. Objetivo e relato de caso: O objetivo é fazer um relato de caso de um paciente de 15 anos, sem comorbidades sistêmicas que foi diagnosticada com dengue (DENV) e infecção odontogênica do elemento 16, acometendo o seio maxilar, espaço bucal maxilar e subpalpebral direito. O tratamento foi realizado, notando-se um atraso na resposta da melhora clínica da infecção odontogênica, evidenciando a necessidade de prevenção das duas condições clínicas comuns. Conclusão: Sugerindo que a dengue pode agravar o quadro de infecção dentária devido a alteração nas condições imunológicas do paciente, dificultando seu tratamento.
\end{abstract}

Palavras-chave: Dengue; Infecção dentária; Tratamento odontológico.

\begin{abstract}
Background: Dengue is an endemic viral disease transmitted by mosquitoes of the species Aedes aegypti and Aedes albopictus that causes a fall in the host's immune system due to overload in fighting the virus and leaves the body more susceptible to opportunistic infections. The odontogenic infection can have its condition aggravated in patients infected with dengue, making the treatment more complex. Objective and case report: The objective is to make a case report of a 15-year-old patient, without systemic comorbidities who was diagnosed with dengue (DENV) and element 16 odontogenic infection, affecting the maxillary sinus, maxillary and right subpalpebral oral space. The treatment was carried out, noting a delay in the response of the clinical improvement of the odontogenic infection, showing the need for prevention of the two common clinical conditions. Conclusion: Suggesting that dengue can worsen the condition of dental infection due to changes in the patient's immunological conditions, making treatment difficult.
\end{abstract}

Keywords: Dengue; Tooth infection; Dental treatment.

\title{
Resumen
}

Antecedentes: el dengue es una enfermedad viral endémica transmitida por mosquitos de las especies Aedes aegypti y Aedes albopictus que provoca una caída en el sistema inmunológico del huésped debido a la sobrecarga en la lucha contra el virus y deja el organismo más susceptible a infecciones oportunistas. La infección odontogénica puede tener su condición agravada en pacientes infectados con dengue, haciendo más complejo el tratamiento. Objetivo y reporte de caso: El objetivo es realizar un reporte de caso de un paciente de 15 años, sin comorbilidades sistémicas, que fue diagnosticado de dengue (DENV) e infección odontogénica del elemento 16, afectando el seno maxilar, espacio oral maxilar y subpalpebral derecho. El tratamiento se llevó a cabo, notando un retraso en la respuesta de la mejoría clínica de la infección odontogénica, mostrando la necesidad de prevención de las dos condiciones clínicas comunes. Conclusión: Sugerir que el dengue puede empeorar la condición de infección dental debido a cambios en las condiciones inmunológicas del paciente, dificultando el tratamiento.

Palabras clave: Dengue; Infección dental; Tratamiento dental.

\section{Introdução}

A dengue constitui uma doença viral endêmica transmitida pela fêmea do mosquito Aedes aegypti e Aedes albopictus que se favorecem de condições meteorológicas e de hábitos humanos e infectam mais de 390 milhões de pessoas por ano no mundo (Pulsan et al., 2020; Vargas et al., 2020). Desencadeia sintomas que vão desde mialgia acompanhada por febre até o desenvolvimento choque hipovolêmico em casos mais graves. Seu diagnóstico ocorre de forma clínica-laboratorial, com investigação da situação na região ou cidade do infectado e, a partir dele, o paciente é classificado segundo o seu estadiamento clínico (Araújo et al., 2021; Libraty et al., 2002 e Lupi, Carneiro \& Coelho, 2007).

Após a inoculação, o vírus multiplica-se através do sistema linfático e entra na circulação sanguínea do hospedeiro e permanece incubado de 4 a 7 dias (Lupi, Carneiro \& Coelho 2007). A infecção é capaz de desencadear uma resposta inflamatória sistêmica, com uma diminuição progressiva nas funções das células T e um aumento da apoptose, o que leva a uma maior disseminação do vírus para outras células e diminuição da resposta imune do hospedeiro. Com isso, infecções oportunistas podem ser desencadeadas a partir um quadro de baixa da imunidade causado pelo vírus da dengue (DENV) (Libraty et al., 2002; Pulsan et al., 2020).

Infecções de cabeça e pescoço na maioria das vezes possuem uma origem dentária envolvendo espécies bacterianas tanto aeróbicas quanto anaeróbicas, as quais fazem parte da microbiota nativa do organismo, o que justifica seu caráter 
oportunista, na qual geralmente se tratadas de forma efetiva não traz complicações. No entanto, a dengue pode favorecer a progressão da infecção odontogênica para espaços faciais profundos, o que aumenta a morbidade e mortalidade do paciente. Além de que, pode-se observar um atraso na melhora clínica da infecção dentaria, mesmo quando empregado uma conduta agressiva para melhora rápida do quadro, devido a condição sistêmica do paciente desencadeada pela doença viral (Gotz et al., 2015; Melo et al., 2021; Zirk et al., 2016).

Objetiva-se, a partir disso, relatar o papel da contaminação pelo vírus da dengue (DENV) como fator de risco para evolução de infecção odontogênica.

\section{Metodologia}

Trata-se de um estudo retrospectivo, descritivo e observacional no formato de Relato de Caso Clínico de um paciente tratado em ambiente hospitalar. Os dados epidemiológicos, história da doença e registros fotográficos foram coletados através do prontuário físico e eletrônico, após autorização dos responsáveis pelo paciente, mediante a assinatura do Termo de Consentimento Livre e Esclarecido (TCLE), seguindo os preceitos para publicação sem a identificação do paciente. Como meio de complemento e embasamento do estudo, foram feitas buscas na literatura utilizando o MeSH Database através da padronização de palavras chave. Com base na busca, foi feita uma breve discussão conforme o que foi encontrado na literatura e descrito o diagnóstico e tratamento, visando os melhores resultados para o paciente.

\section{Relato de Caso}

Paciente de 15 anos do sexo feminino, saudável, ASA I foi atendida pela equipe médica em ambiente hospitalar, queixando-se de febre, adinamia, mialgia, cefaléia e dor retro orbitária com persistência de 2 dias, tendo o diagnóstico pela equipe médica de dengue. A mesma foi medicada e orientada quanto aos cuidados e foi liberada. No $6^{\circ}$ dia após a alta hospitalar a paciente apresentou dor dentária no primeiro molar superior direito, com edema extraoral do lado, trismo, febre, disfagia, dispnéia, disfonia, ortopnéia e drenagem espontânea pelo palato (Figura 1 A). No exame tomográfico foi notado envolvimento do seio maxilar direito, espaço bucal e infraorbitário ipsilateral (Figura 1 B-C). No exame laboratorial, foi possível observar valores de leucócitos de $14500 \mathrm{~mm}^{3}$ e PCR 224,9 mg/dL.

A paciente foi internada e medicada com 500mg de hidrocortisona e antibioticoterapia, Clindamicina (600mg de 8 em 8 horas) e Ceftriaxona (1g de $12 \mathrm{em} 12$ horas) por via endovenosa. A drenagem cirúrgica, remoção do dente envolvido, e instalação de dreno foi realizada sob anestesia geral por acesso intraoral (Figura 1 D-E). Após 48 horas, a paciente apresentava edema considerável com drenagem espontânea de pus via dreno, com atraso no processo de cura da infecção (Figura 1 F). A antibioticoterapia foi mantida com lavagem intrabucal com solução salina $0,9 \%$ por 3 dias foi realizada. A paciente então começou a apresentar melhora clínica com diminuição do trismo, já não apresentava mais disfagia, dispnéia e febre; e também pode-se observar uma melhora laboratorial com normalização nos leucócitos $7358 \mathrm{~mm}^{3}$, apenas o PCR apresentava-se um pouco aumentado com $21,8 \mathrm{mg} / \mathrm{dL}$, porém a paciente teve alta hospitalar após 6 dias de internação. 
Figura 1 - A- Aspecto extraoral pré operatório, evidenciando tumefação do lado direito da face. B - C- Tomografia computadorizada corte coronal (B) e corte axial (C) evidenciando o envolvimento do seio maxilar, espaço bucal e infraorbitário ipsilateral. D - E - Acesso intraoral ao seio maxilar com drenagem de coleção purulenta. F- Aspecto extraoral com 24 horas de pós operatório, evidenciando edema considerável no lado direito da face.

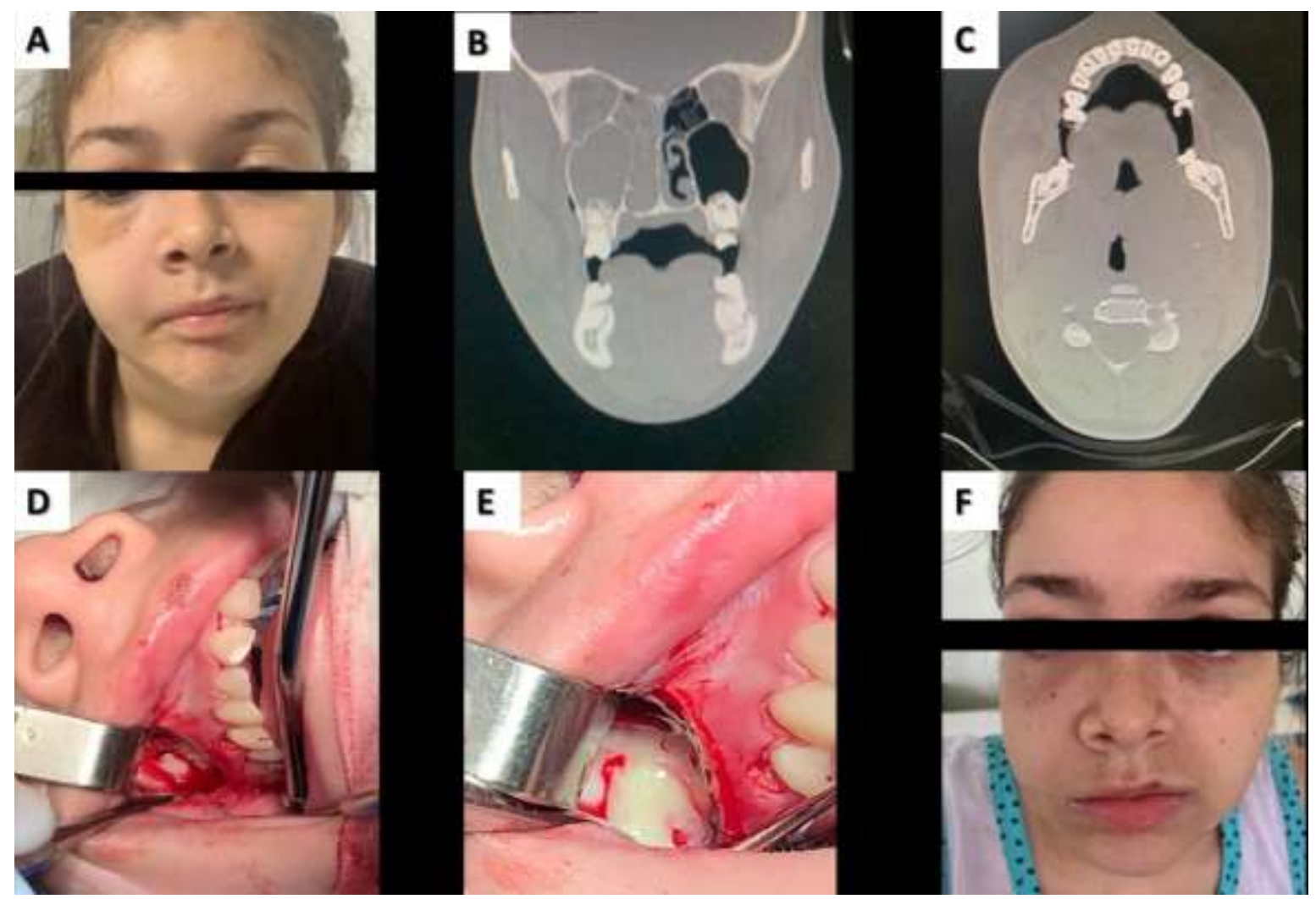

Importante observar a secreção purulenta envolvendo o seio maxilar, por onde foi possível realizar a drenagem intraoral. Fonte: Autores (2020).

\section{Discussão}

A dengue é uma infecção viral febril de evolução aguda transmitida por um vírus da família Flaviridae e é adquirida pelo hospedeiro através da picada do mosquito quando este se alimenta do sangue de uma pessoa infectada. Existem 4 variações de sorotipo do vírus: DENV-1, DENV-2, DENV-3 e DENV-4. A resposta diante da infecção pode ter reações sintomáticas e assintomáticas, sendo que o percentual de infecções assintomáticas está relacionado a fatores ambientais, individuais como o sistema imunológico do sujeito; do vetor e do próprio vírus (Lupi, Carneiro \& Coelho, 2007, Pulsan et al., 2020 e Muhammad Azami et al., 2020).

Na forma clássica, o paciente pode apresentar febre de início súbito com duração de 3 dias, podendo manter-se por até 8 dias e chegar até $40^{\circ} \mathrm{C}$. Nesse caso, o paciente geralmente queixa-se de artralgia, mialgia especialmente na região lombar e membros inferiores; cefaléia de localização retro orbitária, náuseas, disgeusia, prostração e anorexia; ocorre também, no início, erupção cutânea e após 3 a 4 dias, o exantema maculopapular fica mais evidente, podendo ter até sensação de queimação. As manifestações hemorrágicas podem ocorrer em 5 a $30 \%$ dos casos e apresenta os mesmos sinais e sintomas da dengue clássica juntamente a gengivorragia, epistaxe ou metrorragia e petéquias de aparecimento no terceiro ou quarto dia, que são analisadas em exames específicos. Nessas manifestações, principalmente após o $3^{\circ}$ dia, os pacientes devem ter um acompanhamento mais rigoroso, pois é a partir desse período que podem apresentar sinais e sintomas que precedem a gravidade da doença e 
caracterizam-se com hemoconcentração (extravasamento plasmático) e plaquetopenia, com sangramento espontâneo principalmente do trato digestivo e urinário (Lupi, Carneiro \& Coelho, 2007, Zirk et al., 2016, Pulsan et al., 2020, Vargas, Cime-Castilho \& Lanz-Mensoza, 2020)

Os processos envolvidos no combate ao vírus da dengue (DENV) causam uma diminuição na efetividade da resposta imunológica do hospedeiro pela sobrecarga e pela linfopenia, que ocorre em alguns casos, o que prejudica a ativação celular, migração de células e apoptose ${ }^{8}$. Essas alterações podem ser observadas em exames laboratoriais utilizados para medir a severidade e evolução da infecção viral. No hemograma completo, nos primeiros 3 dias de febre na dengue clássica, pode-se observar leucopenia e neutropenia; a trombocitopenia pode ser observada em 35 a $50 \%$ dos casos, e o hematócrito, hemoglobina e as provas de coagulação são normais.

No caso da hemorrágica, há uma leucopenia no início, com predomínio de neutrófilos e durante a agudização, pode ser observada linfocitose com 15 a 20\% de linfócitos atípicos. Com a evolução, há uma queda abrupta de plaquetas e/ou aumento do hematócrito, o que reflete no extravasamento de plasma; anormalidades na coagulação também são observados e há uma correlação entre os níveis de hematócrito, perda de volume plasmático e a gravidade da doença (Lupi, Carneiro e Coelho 2007). No presente caso, a paciente apresentava um quadro de dengue comum sem sintomatologia importante, porém com leve alteração de hemograma, mas causando redução da resposta imunológica pela sobrecarga no combate ao vírus e dificultando o tratamento da infecção odontogênica, pois normalmente após feita a drenagem, estabelecimento da antibioticoterapia e remoção da causa em um paciente saudável, o paciente apresenta melhora considerável do quadro, o que aconteceu com essa paciente (Zirk et al., 2016).

O diagnóstico das infecções odontogênicas deve ser feito de maneira rápida e tratado corretamente. Esse relato apresenta uma associação importante de um quadro de Dengue favorecendo a progressão de uma infecção bucal, isso porque os casos de dengue estão cada vez mais frequentes (Muhammad Azami et al., 2020). Isso nos chama a atenção para buscar informações completares na anamnese que sugerem um quadro de dengue do paciente, preparando o cirurgião para um tratamento mais agressivo da infecção odontogênica. Nesse caso, mesmo com a evolução rápida e maior gravidade da infecção odontogênica, o tratamento ocorreu sem complicações em âmbito hospitalar, porem com um maior período de internação.

A prevenção, tanto da infecção odontogênica quanto da dengue, é o melhor método para diminuir a ocorrências destas (Abreu et al., 2021; Pulsan et al., 2020 e Muhammad Azami et al., 2020). No caso da infecção bacteriana, a prevenção se dá a partir de medidas de higienização bucal e de visitas periódicas ao Cirurgião Dentista; no caso, se não houvesse um quadro odontológico já estabelecido, a gravidade da infecção poderia ser menor ou sequer ela seria instalada, mesmo com certo desequilíbrio entre a resposta do hospedeiro e a virulência do microrganismo. Enquanto que para a dengue, a prevenção se dá a partir da intensificação e fortalecimento dos programas de vigilância simultaneamente com a conscientização da comunidade e medidas de saúde pública para redução de mosquitos (Pulsan et al., 2020).

\section{Conclusão}

Sugere-se que a Dengue interfere negativamente na capacidade de defesa do organismo combater uma infeç̧ão odontogênica, no entanto estudos clínicos prospectivos são necessários para avaliar esta relação.

\section{Referências}

Abreu, G. J., Queiroz, C. M., Soares, F. V., Fernandes, I. L. dos S., Carvalho, N. A. de, Cruz, B. L. S., Viana, J. A. S. M., Silva, P. P. da, \& Gonçalves, G. K. N. (2021). Health education for children: strategy to combat dengue. Research, Society and Development, 10(1), e2110110864. https://doi.org/10.33448/rsdv10i1.10864 
Research, Society and Development, v. 10, n. 4, e14010413930, 2021

(CC BY 4.0) | ISSN 2525-3409 | DOI: http://dx.doi.org/10.33448/rsd-v10i4.13930

Araújo, M. L. V., Nascimento Filho, A., Cordeiro, A., Sampaio, R., Moret, M., Rosário, R., Miranda, J. G. V., Macedo, M., Jorge, E., \& Saba, H. (2021). Correlação espaço-temporal da dengue e variáveis climáticas na cidade de São Paulo, Brasil. Pesquisa, Sociedade e Desenvolvimento, 10 (3), e7010313067. https://doi.org/10.33448/rsd-v10i3.13067

Bali, R. K., Sharma, P., Gaba, S., Kaur, A., \& Ghanghas, P. (2015). A review of complications of odontogenic infections. National journal of maxillofacial surgery, 6(2), 136-143. Doi:10.4103/0975-5950.183867

Götz, C., Reinhart, E., Wolff, K. D., \& Kolk, A. (2015). Oral soft tissue infections: causes, therapeutic approaches and microbiological spectrum with focus on antibiotic treatment. Journal of cranio-maxillo-facial surgery: official publication of the European Association for Cranio-Maxillo-Facial Surgery, 43(9), 1849-1854. 10.1016/j.jcms.2015.08.002

Heim, N., Wiedemeyer, V., Reich, R. H., \& Martini, M. (2018). The role of C-reactive protein and white blood cell count in the prediction of length of stay in hospital and severity of odontogenic abscess. Journal of cranio-maxillo-facial surgery: official publication of the European Association for Cranio-MaxilloFacial Surgery, 46(12), 2220-2226. 10.1016/j.jcms.2018.10.013

Katoumas, K., Anterriotis, D., Fyrgiola, M., Lianou, V., Triantafylou, D., \& Dimopoulos, I. (2019). Epidemiological analysis of management of severe odontogenic infections before referral to the emergency department. Journal of cranio-maxillo-facial surgery: official publication of the European Association for Cranio-Maxillo-Facial Surgery, 47(8), 1292-1299. Doi:10.1016/j.jcms.2019.05.002.

Libraty, D. H., Endy, T. P., Houng, H. S., Green, S., Kalayanarooj, S., Suntayakorn, S., et al. (2002). Differing influences of virus burden and immune activation on disease severity on secondary dengue-3 virus infections. The Journal of Infectious Diseases; 185, 1213-1221. 10.1086/340365

Lupi, O., Carneiro, C. G., \& Coelho, I. C. B. (2007). Manifestações mucocutâneas da dengue. An. Bras. Dermatol. 82, 291-305.

Melo, R. B., Lima, E. B., Sá, C. D. L., Feitosa, V. P., Ramos, T. M. M., \& Tchemra, F. G. C. (2021). Acidente vascular cerebral associado a infecção odontogênica grave em paciente geriátrico - relato de caso. Pesquisa, Sociedade e Desenvolvimento, 10 (1), e47110111950. https://doi.org/10.33448/rsdv10i1.11950

Muhammad Azami, N. A., Takasaki, T., Kurane, I., \& Moi, M. L. (2020). Non-Human Primate Models of Dengue Virus Infection: A Comparison of Viremia Levels and Antibody Responses during Primary and Secondary Infection among Old World and New World Monkeys. Pathogens (Basel, Switzerland), 9(4), 247. 10.3390/pathogens 9040247.

Pulsan, F., Sobi, K., Anga, G., Vince, J., Duke, T. (2020). An outbreak of dengue fever in children in the national capital district of Papua New Guinea in 2016. Pardiatr Int Child Health. 1-4. 10.1080 / 20469047.2020.1756106

Vargas, V., Cime-Castillo, J., \& Lanz-Mendoza, H. (2020). Immune priming with inactive dengue virus during the larval stage of Aedes aegypti protects against the infection in adult mosquitoes. Scientific reports, 10(1), 6723. 10.1038/s41598-020-63402-z

Zirk, M., Buller, J., Goeddertz, P., Rothamel, D., Dreiseidler, T., Zöller, J. E., \& Kreppel, M. (2016). Empiric systemic antibiotics for hospitalized patients with severe odontogenic infections. Journal of cranio-maxillo-facial surgery: official publication of the European Association for Cranio-Maxillo-Facial Surgery, 44(8), 1081-1088. Doi:10.1016/j.jcms.2016.05.019. 